\title{
ELEVATING LEADERSHIP DEVELOPMENT PRACTICES TO MEET EMERGING NEEDS
}

\section{Abstract}

The changing landscape that leaders face demands an evolution of leadership development that not only builds skills but also grows a leader's capacity to effectively respond to and manage an ambiguous, uncertain and changing future. Based on adult development theory, we explore the nuanced difference of leadership development through two distinct, but equally useful lenses: horizontal and vertical leadership development. We examined the state of leadership development practice across fifteen large organizations and present differences in how six common leadership development practices including assessments, individual development plans, expert knowledge sharing, mentorship, coaching, and experiential opportunities were used in a more traditional skill-building way, and how principles of vertical development were incorporated. We conclude with specific practical approaches to modify traditional practices to meet emerging needs.

\section{Introduction}

Have the demands of an increasingly complex and ambiguous environment eclipsed our approach to developing leaders? Industry surveys (PwC, 2017; Deloitte, 2017) and provocative scholarship (Pfeffer, 2015) paint a consistent picture of a shortage of leaders prepared for the disruptive nature of the digital age. To maintain the essential capacity of strategic agility, leaders today must be capable of managing paradoxical tensions, sensing new possibilities and perspectives, and making complex decisions quickly and effectively (Lewis, Andriopoulos, \& Smith, 2014). While these capacities have been identified and are agreed upon as important by organizations and scholars, they are difficult to effectively and consistently demonstrate. Currently less than $10 \%$ of leaders have the qualities of mind to optimally lead in volatile, uncertain, complex and ambiguous (VUCA) environments (Ghemawat,
2012; Leslie, 2009). This shortage of prepared leaders is often referred to as 'The Leadership Gap', a concept that emphasizes the growing difference between the leadership skills currently possessed by leaders in today's organizations, and the skills that are needed to solve the complex problems of the future (Weiss \& Molinaro, 2005).

The way out of this seeming dilemma may lie in understanding the distinctions and providing a bridge between two equally useful approaches referred to as horizontal development and vertical development. Both play an important role, but only vertical development is designed to meet the complex demands of leadership today. Let's explore the distinctions more closely (see Table 1). 
Table 1.

Horizontal and Vertical Development Compared

\begin{tabular}{|l|l|}
\hline \multicolumn{1}{|c|}{ Horizontal Development } & \multicolumn{1}{c|}{ Vertical Development } \\
\hline Traditional leadership development programs & $\begin{array}{l}\text { An emerging, evidence-based set of best } \\
\text { practices }\end{array}$ \\
\hline $\begin{array}{l}\text { Focus on building skills and adding } \\
\text { competencies }\end{array}$ & $\begin{array}{l}\text { Focus on growing the mindset agility that } \\
\text { leads to strategic thinking }\end{array}$ \\
\hline Do what we already know how to do better & $\begin{array}{l}\text { Learn how to lead in a dynamic, complex } \\
\text { and uncertain world }\end{array}$ \\
\hline
\end{tabular}

I use vertical development assessments.

The ones I use most often are the Lexical

The majority of leadership time and money is invested in the realm of traditional/horizontal development where the focus is on preparing leaders to successfully achieve stated objectives and building mastery in areas with relatively well defined and agreed upon outcomes. Competency models and skills training on topics like communication, decision analysis, quality management, emotional intelligence and team building as well as technically specific skills also fit here.

Vertical development is concerned with intentionally cultivating increasingly sophisticated and agile leadership mindsets. These qualities of mind are characterized by maturity in perspective-taking, ability to deal with uncertainty and ambiguity, comfort challenging assumptions in self and others and the capacity to learn and integrate new understanding into action (Allen \& Wergin, 2009; Helsing \& Howell, 2014).

Grounded in research that suggests adults continue to grow and develop through their lifespan (Kegan, 1982), vertical development is more of a journey in mental complexity, rather than a destination towards skills-based mastery. The vertical development journey is typically defined as moving through stages characterized by different motivations, behaviors and decision- making orientations to self, others, and the environment (Loevinger, 1976; Cook-Greuter \&
Miller, 1994; Rooke \& Torbert, 2005; Kegan \& Lahey, 2010) (See Figure 1). Most leaders (80\%) occupy the conventional stage while emerging complexities call for the higher order of mental complexity found in post-conventional stages, a space too few leaders (15\%) occupy today (Rooke \& Torbert, 2005). 


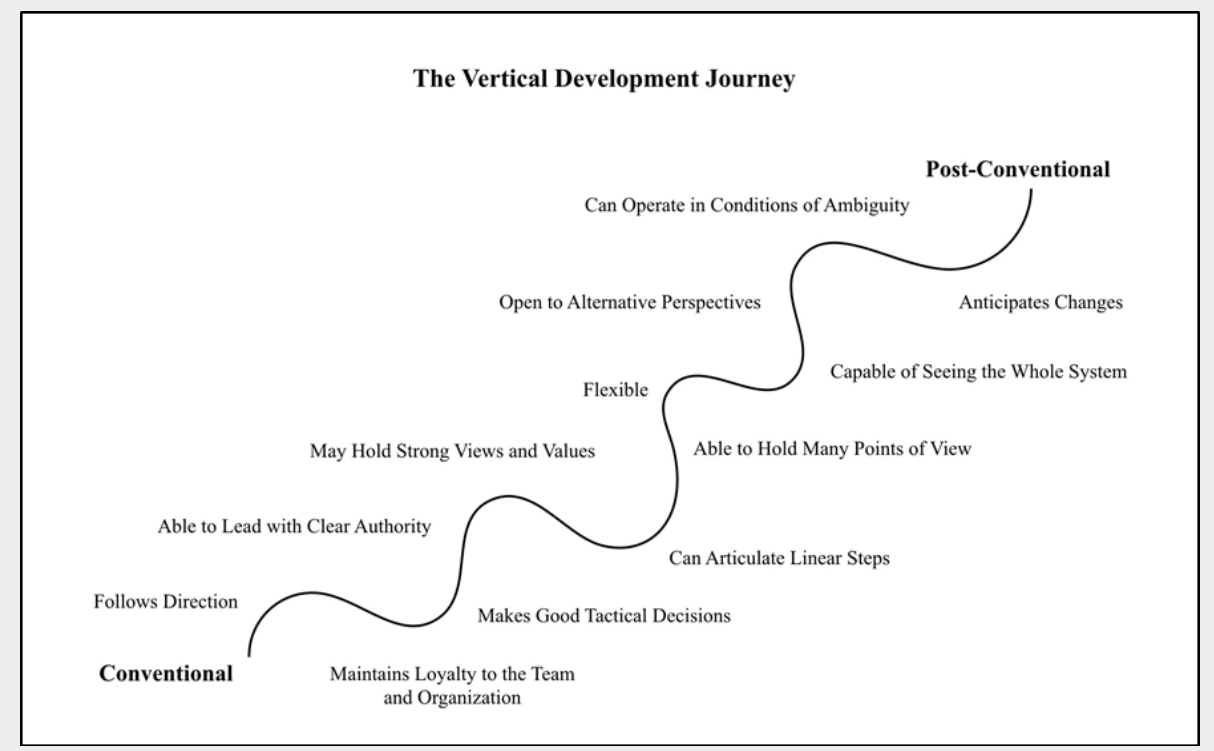

Figure 1. The Vertical Development Journey

What distinguishes practices that support vertical development from horizontal development? Research (Manners \& Durkin, 2000) suggests that experiences characterized as: personally salient, interpersonal in nature, emotionally engaging and challenging yet open to positive interpretation and disequilibrium will support vertical development. Vincent, Ward and Denson (2015) found that additional psychosocial challenges including intentional ambiguity, exposure to diverse perspectives, deep self-reflection, learning from experience, experimentation and risk-taking all promoted shifts from conventional to postconventional stages. While not explicitly considered in adult development theory, recent research suggests that psychological safety (Edmonson \& Lei, 2014; Boyatzis \& Jack, 2018) is also critical as it allows the vulnerability required for learning.

The leadership gap described earlier may be more of a consciousness gap than a skills gap. Building a bridge requires an understanding of the two shores one wishes to transverse. While there are consulting and practice models (Petrie, 2014, 2015; Berger, 2012; Kegan \& Lahey, 2009) that purport to support vertical growth, there have been no investigations of how common talent management practices align with the principles that support vertical growth. Therefore, the objective of our study was to examine the current state of practice through these two lenses (horizontal and vertical) and provide suggestions to support more vertical growth.

\section{Method}

To understand the state of practice we interviewed nineteen internal leaders responsible for leadership development (LD) in their organization and six external leadership development consultants. The nineteen internal practitioners came from fifteen large (over 1,000 employees) organizations in the technology, professional services, manufacturing, healthcare and government/philanthropy industry sectors (see Table 2). 
Table 2.

Respondent Organizations by Industry

\begin{tabular}{|l|l|}
\hline \multicolumn{1}{|c|}{ Industry } & \multicolumn{1}{c|}{$\begin{array}{c}\text { Number of } \\
\text { Organizations }\end{array}$} \\
\hline Technology & 7 \\
\hline Professional or Financial Services & 2 \\
\hline Manufacturing & 1 \\
\hline Healthcare and Pharmaceuticals & 2 \\
\hline Government or Philanthropy & 3 \\
\hline
\end{tabular}

Of the fifteen organizations, four were intentionally using a vertical development approach, and of those four, two were using this approach across all levels of leaders. Regardless of whether the organization intentionally used a vertical approach, all organizations used several universally accepted leadership development practices including assessments, individual development plans, expert knowledge sharing, mentorship, coaching, and experiential opportunities. While these practices are similar in definition, there was a significant difference in the way they were implemented by those using a more traditional horizontal approach and those using a vertical approach to leadership development. Below we describe each practice and provide examples using the words of our respondents. Their voice helps make the differences in how these leadership development practices are implemented come alive. We conclude each section with recommendations for how to adjust each practice to be more vertically developmental.

\section{Common Leadership Development Practices Using Horizontal and Vertical Approaches}

Assessments using a Horizontal Approach. It is estimated that 82 percent of organizations utilize assessments for leadership development (Kantrowitz, T., Tuzinski, K. \& Raines, J., 2018). Those implementing horizontal approaches to assessments tend to focus heavily on quantitative data that can be gathered at scale more easily. There is an emphasis on understanding the data and crunching the numbers to gather insights, rather than engaging the system more broadly or seeking different data sources. For example:

$$
\begin{aligned}
& \text { With our engagement survey, last year we } \\
& \text { came out with guides for how managers } \\
& \text { could talk to their teams about their own } \\
& \text { manager effectiveness scores-which I } \\
& \text { think was relatively new for a lot of our } \\
& \text { managers. We never mandate things, } \\
& \text { so you know, some managers did it and } \\
& \text { some didn't. }
\end{aligned}
$$

Assessments using a Vertical Approach. A vertical approach on the other hand, tends to use a broader set of data from multiple sources and instruments and is situated in the personal story of the leader. There is also an emphasis on following up with individuals, using the data as a way to start conversations that provide further feedback on both current behaviors and planned growth areas. Two internal LD leaders described their approaches:

The assessment that I do with leaders are these four-hour assessments that are biographical and career oriented. We talk about their life history, how that has impacted their values structure, how they bring that into work, their career history, how that has affected their experience, how they see themselves as leaders, and their strengths and their development areas... 
I use vertical development assessments. The ones I use most often are the Lexical Decision-Making Assessment, the LDMA, and the Global Leadership Profile, which measures someone's action logic. Then I use a 360 that has correlation with vertical development, the Leadership Circle 360... So the engagement starts out with a series of assessments. I do the assessments to get a baseline and then I will do them again later during the engagement.

The Idea in Practice: To make your assessment process more vertically developmental use multiple sources including interviews, with both the leader and their peers/stakeholders. Connect the process to a meaningful personal and professional challenge and contextualize the feedback in the leader's story.

Individual Development Plans using a Horizontal Approach. Leadership development practices have long focused on how to improve the performance of individuals, through specific goals and assignments. Originally this approach was primarily deficit-based, focused on improving in areas where leaders were weak. Today many practitioners are pairing or even replacing this with a strengths-based approach that seeks to leverage and magnify a leader's current skills. Regardless of whether a strength or deficit-based approach is being used, horizontal practices involve goal setting in-line with organizational strategy or performance expectations. The larger context of business performance is used to determine areas for growth that support the performance of both the leader and the business. There is an emphasis on measurable results and metrics to track change over time. This usually occurs within the context of a larger process, like performance management, or promotion. While individual development plans are widely used to target this level of individual performance, many employees find the overall exercise to be more bureaucratic than developmental (Zenger, Folkman, \& Palevitz, 2016). Two internal practitioners framed their individual development plan process:

We have a competency framework with eight competencies. ... We use the competencies to design training, we use them to frame performance reviews where we look at who is ready now, who will be ready in a couple of years, and what kind of developmental plan do they need to have based on the competencies. ... We can then see what competencies people have and what we might need to train them in.

We have some challenges in our performance review process, which is done twice annually. It only studies one half of the year at a time. It asks employees to rate themselves, and for others to rate them, based on only one half [of the year], and what impact they made that half. What they found is that it is not rewarding any long-term changes. And there is nothing on there about 'How did you learn? How did you fail?' So our process doesn't really encourage people to set challenging goals or take risks.

Individual Development Plans using a Vertical Approach. In vertical development the growth goals for a leader are defined more broadly, including quantitative and qualitative data, and are not confined to a performance process or matrix of expectations. They are also emergent and iterative. While not tied to a specific performance process, a vertical developmental approach does emphasize the business relevance of individual goals and seeks to connect the work to the leader's daily experience. These vertically developmental goals and assignments do track observable behavior but are less focused on measurable metrics in favor of creating more personalized growth experiences that help to shape a leader's mindset, rather than just change their behavior. Two external coaches explained:

Practically what rolls out is that we identify specific high-impact areas for them to work on. Let me show you... So this is for one of the executives I am working with. He has 
an area of focus of grounded authenticity and he has a specific practical area of behavior change that he is working on. One of them is working on interacting with people without blame or judgment. Now this is about his shadow stuff, because when that is there it is getting in the way of him engaging people.

The process of coming up with a personal action plan is a multi-session dialogue where I have them look across all of the data they got from their assessments and we essentially begin drafting what we think would be high-impact areas to work on. In this case they have to be observable behavioral changes. ... Then we send our best guess as to what these behavioral changes should be out to the people they work with so they get kind of a round of feedback as well. That helps to get them enrolled in it, and it offers up any additional perspectives that the leader might not have seen which helps them get closer to the issues.

The Idea in Practice: To make individual development plans more vertically developmental, increase emergence by moving away from prescribed metrics and predefined content and work with leaders to find measures that are relevant to them, their work, their mindset and their development.

Expert Knowledge Sharing using a Horizontal Approach. While often not a distinct practice in itself, bringing in outside experts to share knowledge and stimulate ideas has long been a practice in organizational leadership development. Whether it is part of a classroom-based training, a coaching experience, or a large leadership event, organizations emphasize the importance of exposing their top leaders to valuable knowledge that is relevant to their field and their role. In horizontal practices this knowledge sharing usually takes the form of a keynote presentation, the sharing of literature, or using an outside training program. These organizations also send top leaders out to other companies and academic institutions to get exposure to expert knowledge. For example, two global organizations expressed:

So once directors get promoted to this level they come to a program. It's two days and it congregates folks around the world to celebrate their promotion, but we also make it an opportunity for learning. The themes this year are largely based around the Digital Landscape and Client Centricity. ... An external consulting firm came in and presented on that topic.

We do a speaker series. So, we have different people coming in. Maybe the topic is resilience... and we have different people come in and share a perspective on the topic. So, it's like that, where we are trying to be less about the theory and more about the practice.

Expert Knowledge Sharing using a Vertical Approach. In a vertical approach the emphasis is placed not on the receiving of expert knowledge but the integrating of expert knowledge. While traditional keynotes and literature are still used, they are likely to introduce leaders to a broader world view, challenge their current beliefs and are accompanied by an experience designed to help leaders apply the new knowledge in a relevant way. There is a strong recognition among vertical developmental practitioners that without using, interacting with, integrating, and applying the new and challenging knowledge it will not be meaningful for the leader's development. Two internal practitioners from tech organizations shared:

As we reflect on how people are thinking about something, I may challenge it by introducing a framework that helps them think about it more holistically and systemically. Then they get to think and reflect and in essence, upgrade their principles that they considered in the beginning. Then immediately say, okay think about what you are working on, think about the next meeting you are going to 
have with your team, how are you going to talk about this, what could be different?

When I think about it, our role [as internal practitioners] is really in being the curator rather than the conduit. We want to bring in those colliding perspectives, we want to spark those experiences, and that means we can't always own them...

The Idea in Practice: To make the process of sharing expert knowledge more vertically developmental, bring the expert off the stage and into contact with leaders, either in-person or through frame-breaking, engaging content that helps the leader integrate the information.

Mentorship using a Horizontal Approach. Mentorship is a common leadership development practice, with over 70 percent of Fortune 500 companies using the practice; however, organizations using horizontal approaches to leadership development struggle to create meaningful mentorship programs (Jones, 2017). Across large, global organizations in particular, pairing meaningful mentors can be a challenge, as is finding the time to meet as these two quotes from tech companies attest:

We used to have this, platform, well we still technically have it, and it's called Mentor Match. Basically, your profile from Workday, or Linkedln, or someplace, and your skills would get filtered in. Then you would say I want to learn this skill, and the platform would spit out these five people in the company you can reach out to. Then you could ping them and reach out.

I had people in Bangalore who wanted mentorship with some people here and it was complicated because there were both times zones and relevancy of work. I am a little old school in that my favorite mentorship engagements... were when the manager would sit down with me for coffee once a month, that was huge. And it was local. Often, we feel this need to provide a mentoring structure to allow our employees to connect and collaborate across cultures and I keep thinking let's just start with the basics....

Mentorship using a Vertical Approach. Vertical development organizations are overcoming these challenges by utilizing more peer-to-peer learning models, where leaders work side-by-side and support each other on relevant challenges. They are encouraged to work on developmental edges, moving the relationship away from one of giving advice, to one that supports mutual learning through dialogue and curious questions. In some cases, these peer groups are paired with coaches or more senior leaders to support the intentional reflection and learning of the larger group. For example:

The cohort, rather than working on a shared project together, is working on a shared developmental edge together. They collectively identify what the practice areas are that they want to work on, like influencing without authority, dealing with conflict situations. ... They say I want to work on it with this individual in this way. And then they go out and they work on those edges and then they come back and we discuss, okay how did that go for you?... So, it is a nine-month intensive, working on your edge, going out and practicing.

[In the session]...as they redesign their next meeting or initiative, or step, whatever it might be, they are connecting in the room with their thinking partners. If it is a team, I have them work on it together in the session, so it is more natural. If it is individual leaders, I try to pair them up based on an affinity. But either way they work with thinking partners. The key is to challenge each other. The thinking partner isn't there for feedback, it's about asking probing questions and challenging assumptions.

The Idea in Practice: To make mentorship more vertically developmental, create opportunities for 
peers to connect on shared experiences, focusing on mutual development of growth edges.

Coaching using a Horizontal Approach. Coaching as a practice for developing leaders has increased in popularity in recent years and is currently estimated to be over a \$2 billion-dollar industry (Dunlop, 2017). Today, coaches distinguish themselves with varying philosophies and methodologies, but the work of providing leaders with personalized one-on-one support for their development is central. Horizontal development practices tend to utilize performancebased coaching where the work is focused on developing the leader to perform in their core role. Coaching in this fashion is often reserved for more senior or underperforming leaders and delivered by external vendors. In these organizations coaching is not always seen as developmental, but as remedial as these internal practitioners expressed:

If you are getting a coach there must be something wrong with you. ... There are still a lot, if I can say this, old timers, who spent their whole career at [this company], who feel like, why would someone need a coach, what is their problem?

At the beginning of the year you sit down with your coach and go through your ambitions for the year, types of projects you will work on... so all of that gets combined into a set of performance goals for the year. ... Now what we are trying to do is personalize people's development based on the expectations for their role, how they are doing against those expectations and where the gaps are.

Coaching using a Vertical Approach. In vertically developmental organizations coaching loses much of this stigma and is seen increasingly as a common practice for all leaders interested in improving themselves. Coaching in this context is focused less on specific role performance and more on explicit consideration of mindset growth including working with perspective-taking, unconscious bias and the shadow aspects of the leader's behavior. This view was reflected in responses from both internal and external practitioners:

One of the things you are trying to catalyze is perspective-taking, and so the more that you are able to do the subject-object shift around their perspective and get them out, the more distance they have from those and the more they are able to integrate and coordinate those perspectives.

The coaching engagement is a very reflective period. So, if you have those going consistently enough, at least they have those touchpoints. ...where they are getting clear about what different tactic, mindset, strategy, or assumptions would have made an impact in that situation and they are reflecting on it.

The Idea in Practice: To make your coaching program more vertically developmental, shift the emphasis from what the leader does to who the leader is and how they understand and interact with the complexity of their environment.

Experiential Opportunities using a Horizontal Approach. It has long been accepted that experience is an effective teacher when it comes to essential leadership skills (Vincent et al., 2015). To stimulate this learning, organizations use experiential opportunities, or action learning, where leaders are exposed to new ways of thinking or doing things and are often supported to debrief and reflect on their learnings. While experiential learning by definition has the potential to support vertical growth, in horizontal practices these experiential opportunities tend to be in line with an organizational competency models, or matrices of requisite skills. These practices help the organization ensure that leaders have the appropriate learning experiences to progress to the next level of leadership or management. And, while many practitioners recognize that classroombased learning does not facilitate the deepest form of experiential learning, many of the horizontal programs are still instructor-led while they strive to integrate more comprehensive experiential 
opportunities. For example:

Say if the topic is communication, we would rather have them do an assessment, experiment with their results, and then bring in, for lack of a better word, games, that help to demonstrate how people show up. Whether it is an intact team or not there is a lot you can learn. There are things like ropes courses that we do... but those are one-offs so to speak. The real experiential components are the conversations they are having within a cohort and then the resources where they continue to bring it back. We also communicate with the participant's managers, so that they can bring it back and apply it to the workplace and be supported.

We have been moving over the last couple of years, to a greater focus on participant led [development opportunities], which I think is a move that is being made in a lot of organizations. So we have these things that were mandated to talk about but how we get to them, and how we get to what the participants want is a balancing act we have to play. We have a strategic challenge project that participants will come with and then they pick a few challenges that they are going to focus on over the course.

Experiential Opportunities using a Vertical Approach. Organizations using a vertical developmental approach are more likely to introduce experiences that fall outside competencies, skills, or any form of traditional job-based learning. There is a greater emphasis on risk-taking in the context of these experiences, with developmental organizations giving leaders projects with high-stakes and true possibility of failure. These experiences emphasize individual growth over skill acquisition or role preparedness. Two internal practitioners shared:

About 4 years ago our CEO said, 'You know, our corporate strategy goes through 2014 and 2015 and that is it. You have always said that the best way to develop leaders is through experience so here you go.' Here you go, meant that we would use the re-creation of the corporate strategy as a designed experience to accelerate the growth across the whole set of leaders. ... The three of us ended up mentoring them through the whole process. We would know how to put structure in place for the goals and such, but they had to carry everything out or they would get right to the edge of their understanding and say I don't know what to do next...[They] then lead a team of about 25 people from around the world ages 30-58, different functions, different regions, different genders, national origin, everything. And that was the team they lead. The objective was to research, challenge and propose an alternative to what would have just been an incremental change in corporate strategy.

These are great elements for crucible experiences. Completely out of their normal experience, enormous responsibility, a real sense of potential failure...What are the key moments that matter - that are going to accelerate their development and get them to the next level that you need them?...We are using [our high potential group] as what you would call, a pool of developing leaders, using succession as a targeted way to make sure they are moving along and getting the right experience to grow their mindset.

The Idea in Practice: To make experiential opportunities more vertically developmental move them out of the classroom and create an experience that has real business impact, and a real possibility of failure for the leader while supporting the vulnerability required for learning.

\section{Conclusion}


Examining the current state of leadership development and the demands placed on leaders in today's environment clarifies why "despite large scale investments in management and leadership education, companies still face a 'leadership crisis' in their organizations" (Kegan and Lahey, 2010). We propose reframing the leadership crisis from a skills gap to a consciousness gap to open up new vertical development strategies for making meaningful progress on this challenge. We must shift this paradigm and redefine what it means to develop leaders in our organizations. This crucial shift must first come from within those leading the development efforts: the practitioners themselves. One practitioner in our study articulated the significance of practitioner consciousness in the following way:

I think one thing that is important is have you actually done this work on yourself? I think a lot of practitioners sometimes get in the bad habit of saying oh, you should do all these things, but they themselves haven't actually gone through that process or that inquiry and there is a hypocrisy in that, you know. Sophisticated clients can smell that out after a while. And then if you practice it yourself, you can teach it not just from the mind, but from the body and from the gut and the heart-all these centers of intelligence-because you have actually gone through it. The power of this work comes from it actually transforming you first.

Much of vertical development requires being comfortable with the discomfort that accompanies growth. As the examples provided in this research show, many of the practices that create growth in leaders are designed to challenge their way of seeing themselves and their world. Challenging beliefs in this way requires a state of presence in the practitioner leading the work. For you to show up in your organization as the voice for vertical growth and change you must be able to handle the discomfort that others will experience in the process, while at the same time managing your own discomfort as you grow alongside them. Consider the following ways to build your capacity and resilience for supporting this organizational shift.

- Develop a mindfulness practice to maintain a state of inner and outer equanimity

- Familiarize yourself with the stages of development, including where you find yourself on the developmental continuum

- $\quad$ Find a community of practice to support your learning journey and provide ideas to make your current practices more vertically developmental

Developing leaders is hard. Period. As with any learning and development strategy, successfully implementing vertically developmental practices like those described here, requires an integrated approach and a long-term view. To make lasting change it is essential that organizational practices support one another and not be piecemealed across select practices. Leaders who want to bring these vertically developmental practices to their organization in an integrated and sustainable way are on the vanguard. It requires commitment and diligence to staying the course, even when challenged by your organization's existing systems and culture. Is your organization prepared for this work? Are you prepared? 


\section{References}

Allen, S. \& Wergin, J. (2009). Leadership and adult development theories: Overviews and overlaps, Kravis Leadership Institute. Leadership Review, 9, 3-19.

Berger, J. (2012). Changing on the job: Developing leaders for a complex world. Stanford University Press.

Boyatzis, R. \& Jack, A. (2018). The neuroscience of coaching. Consulting Psychology Journal: Practice and Research, 70(1), 11.

Cook-Greuter, S. \& Miller, M. (Eds.). (1994). Transcendence and mature thought in adulthood: The further reaches of adult development. Rowman and Littlefield.

Deloitte (2017). Global human capital trends. Retrieved 22 October 2018 from https://www2.deloitte.com/ content/dam/Deloitte/global/Documents/About-Deloitte/central-europe/ce-global-human-capital-trends. pdf

Dunlop, C. (2017, October 05). The success and failure of the coaching industry. https://www. forbes.com/sites/forbescoachescouncil/2017/10/05/the-success-and-failure-of-the-coachingindustry/\#2b910b796765.

Edmonson, A. \& Lei, Z. (2014). Psychological safety: The history, renaissance, and future of an interpersonal construct. Annual Review of Organizational Psychology and Organizational Behavior, 1, 23-43.

Ghemawat, P. (2012). Developing global leaders, McKinsey Quarterly 3. mckinsey.com/insights.

Helsing, D., \& Howell, A. (2014). Understanding leadership from the inside out: Assessing leadership potential using constructive-developmental theory. Journal of Management Inquiry, 23(2), 186-204.

Jones, M. (2017, June 05). Why can't companies get mentorship programs right? https://www.theatlantic. com/business/archive/2017/06/corporate-mentorship-programs/528927/.

Kantrowitz, T., Tuzinski, K. \& Raines, J. (2018). 2018 Global Assessment Trends Report, https://www.shl.pt/ UserFiles/File/2018SHLGlobalAssessmentTrendsReport.pdf.

Kegan, R. (1982). The evolving self: Problems and process in human development. Harvard University Press.

Kegan, R. \& Lahey, L. (2009). Immunity to change: How to overcome it and unlock the potential in yourself and your organization. Harvard Business Review Press.

Kegan, R. \& Lahey, L. (2010). Adult development and organizational leadership in Nohria, N., \& Khurana, R. (Eds.), Handbook of leadership theory and practice: an HBS centennial colloquium on advancing leadership. Harvard Business Review Press.

Leslie, J. (2009). The leadership gap: What you need and don't have when it comes to leadership development. https://www.ccl.org/wp-content/uploads/2015/09/Leadership-Gap-What-You-Need.pdf.

Lewis, M., Andriopoulos, C., \& Smith, W. (2014). Paradoxical leadership to enable strategic agility. California Management Review, 56(3), 58-77. 


\section{References}

Loevinger, J. (1976). Ego development. Jossey-Bass.

Manners, J. \& Durkin, K. (2000). Processes involved in adult ego development: A conceptual framework. Developmental Review, 20(1), 475-513.

Petrie, N. (2014). Vertical leadership development-Part 1: Developing leaders. http://www.ccl.org/wpcontent/uploads/2015/04/VerticalLeadersPart1.pdf.

Petrie, N. (2015). The how-to of vertical leadership development—Part 2: 30 experts, 3 conditions and 15 approaches. http://www.ccl.org/wp-content/uploads/2015/04/verticalLeadersPart2.pdf.

Pfeffer, J. (2015). Leadership BS: Fixing workplaces and careers one truth at a time. Harper Business.

PwC. (2017). 20th CEO Survey. Retrieved 22 October 2018 from: https://www.pwc.com/gx/en/ceosurvey/2017/pwc-ceo-20th-survey-report-2017.pdf.

Rooke, D., \& Torbert, W. R. (2005). Seven transformations of leadership. Harvard Business Review, 83, 66-76.

Vincent, N., Ward, L., \& Denson, L. (2015). Promoting post-conventional consciousness in leaders: Australian community leadership programs. The Leadership Quarterly, 26(2), 238-253.

Weiss, D. \& Molinaro, V. (2005). The leadership gap: building leadership capacity for competitive advantage. Wiley.

Zenger, J., Folkman, J., \& Palevitz, J. (2016). Discovering and developing hidden reservoirs of talent: Connecting the strategy and needs of the organization with employees' talents, energy, and passion. http://leadership.zengerfolkman.com. 